\title{
A Review on Effect of Orientation Fabric on Mechanical Energy Absorption Natural Fibres Reinforced Composites
}

\author{
S.N.A Khalid ${ }^{1, a}$, A.E Ismail ${ }^{2, b}$, M.H Zainulabidin ${ }^{3, c}$ \\ ${ }^{1,2,3}$ Faculty of Mechanical and Manufacturing Engineering, Universiti Tun Hussein Onn Malaysia, \\ 86400 Parit Raja, Batu Pahat, Johor, Malaysia \\ asitinorazilabintikhalid@yahoo.com, bemran@uthm.edu.my, chafeez@uthm.edu.my
}

Keywords: Woven Kenaf, Orientation, Energy Absorption, Impact

\begin{abstract}
This paper presents the combination technique in developing the woven kenaf fiber that is used as a new method to improve energy absorption performance. This method focuses on the effect energy absorption of angle orientation. Due to the low density, natural fiber such as kenaf fiber provides comparatively good mechanical properties. Thus, natural fibers have high potential for better reinforcement in light weight structures on automotive applications. Total force, total energy, and energy absorption of natural fibre reinforced composite for different type's natural fibre and angle orientation are reviewed and discussed.
\end{abstract}

\section{Introduction}

In the recent years industry is attempting to reduce the dependence on petroleum based fuels and products due to the increasing environmental consciousness. This leads to the need to investigate environmentally friendly, sustainable materials to replace existing ones. The increase of production and use of plastics in every sector of our life lead to huge plastic wastes. Disposal problems, as well as strong regulations and criteria for cleaner and safer environment, have directed great part of the scientific research toward eco-composite materials. Among the different types of eco-composites, those which contain natural fibres (NF) and natural polymers have a key role [1].

Few studies deal with structural composites based on natural reinforcements. These studies are mainly oriented to the housing applications where structural panels and sandwich beams are manufactured out of natural fibres and used as roofs. Considering the high performance standard of composite materials in terms of durability, maintenance and cost effectiveness, the application of natural fibre reinforced composites as construction material holds enormous potential and is critical for achieving sustainability. Due to their low density and their cellular structure, natural fibre posses very good acoustic and thermal insulation properties and demonstrate many advantageous properties over glass or rockwool fibre example handling and disposal [2]. Recently, some of studies have been carried out to determine the effects of various variables on energy absorption capability of composites material under compressive loading [3, 4].

It is started with the review of kenaf fibre advantages. Then, it is discussed on the characteristic between woven and non-woven natural fibre with focusing the input strength for various types of layers and orientations.

\section{Energy Absorption Factor in Natural Fiber Laminate}

Advantage of kenaf fiber: Research on kenaf natural fibre is increasingly interested among researchers $[5,6]$. In summary, a comparative study of mechanical properties of kenaf fibre reinforced composites and other natural fibre are collected together. The characteristic strength of natural fibre is important to determine material ability, especially under extreme and critical condition, which is directly connected with engineering performance. According to the result, Figure 1 illustrates that kenaf composite have higher modulus compare to other fibres. In this research, kenaf fibres are selected based on their capability of modulus strength. 


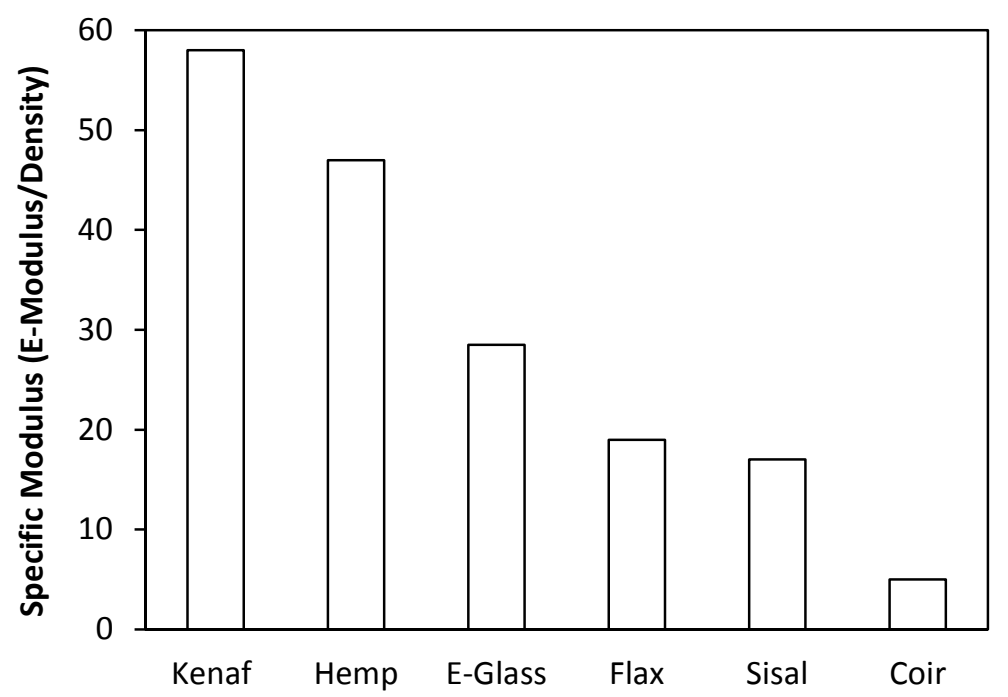

Figure 1: Comparison of specific modulus of kenaf fibre with several other fibres [5]

Characteristic of woven and non-woven: According to some literature [7, 8], woven fibre is have good mechanical properties compare to non-woven. Figure 2 shows the illustration image of unidirectional and woven on jute fabric. Table 1 shows the effect of NWJF (Non-Woven Jute Fabric) and WJF (Woven Jute Fabric) on impact strength of PLLA (Poly L-lactic Acid). The average impact strength of untreated WJF/PLLA composite in warp direction $(16.4 \mathrm{~kJ} / \mathrm{m})$ is $85.9 \%$ higher than the impact strength of unreinforced PLLA. As a result, the strength of the WJF/PLLA fabric composite is greater than the strength in NWJF/PLLA. According to the result, it can be concluded that woven structure exhibited excellent mechanical behaviour under tensile, flexural, and impact loading compare to non-woven composite. It also mention that, tensile, flexural and impact strength of WJF/PLLA composite is higher at warp direction compared to weft direction.

Characteristic of impact test at different layers: Figure 3 shows the variation in energy absorbed with different layers. From the figure, there is an increase in the amount of energy absorption by specimen hemp reinforced compared without reinforcement. It can be seen that energy absorbed by 1 and 2 layers is less than 3 and 4 layers. As can be seen from the result, 1, 4 and 5 layers of hemp reinforced samples absorb total energies of 10.558 and $10.528 \mathrm{~J}$, respectively, which is have a small significant effect. The trend shows that by increases layer up to its threshold value the energy absorbed also increase.

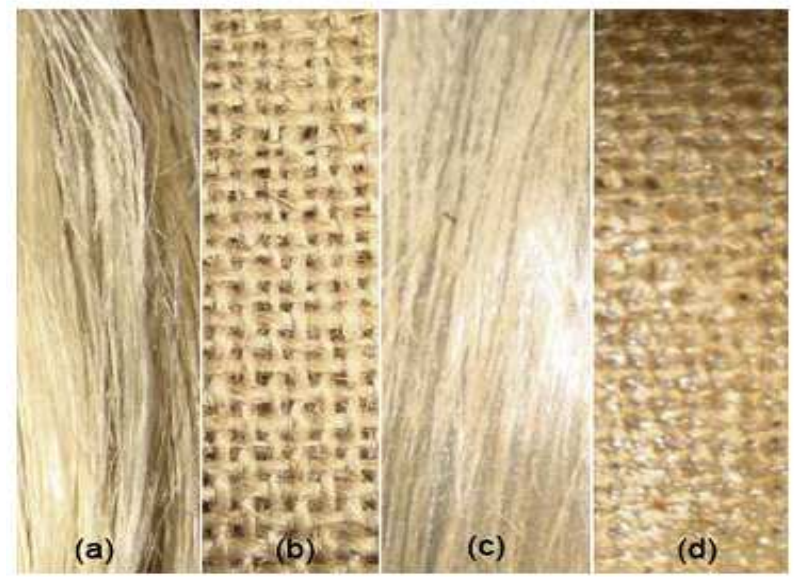

Figure 2: Image of (a) unidirectional jute, (b) plain woven jute fabric, (c) non-woven jute fabric composite and (d) plain woven jute fabric composite [8] 
Table 1: Mechanical properties of jute fabrics/PLLA composite [8]

\begin{tabular}{lcccccc}
\hline \multicolumn{1}{c}{ Sample } & $\begin{array}{c}\text { Tensile } \\
\text { Strength } \\
(\mathrm{MPa})\end{array}$ & $\begin{array}{c}\text { Tensile } \\
\text { Modulus } \\
(\mathrm{GPa})\end{array}$ & $\begin{array}{c}\text { Strain } \\
(\%)\end{array}$ & $\begin{array}{c}\text { Flexural } \\
\text { Strength } \\
(\mathrm{MPa})\end{array}$ & $\begin{array}{c}\text { Flexural } \\
\text { Modulus } \\
(\mathrm{GPa})\end{array}$ & $\begin{array}{c}\text { Impact } \\
\text { Strength } \\
\left(\mathrm{kJ} / \mathrm{m}^{2}\right)\end{array}$ \\
\hline $\begin{array}{l}\text { 1. Unreinforced } \\
\quad \text { PLLA }\end{array}$ & $40 \pm 6.3$ & $0.36 \pm 0.001$ & 3.4 & $42 \pm 9.7$ & $3.02 \pm 0.8$ & $8.82 \pm 0.9$ \\
$\begin{array}{l}\text { 2. NWJF/PLLA } \\
\text { composite }\end{array}$ & $55 \pm 11.5$ & $0.867 \pm 0.02$ & 6.01 & $67 \pm 8.4$ & $2.83 \pm 1.1$ & $13 \pm 1.1$ \\
\hline $\begin{array}{l}\text { At warp direction: } \\
\begin{array}{l}\text { Untreated } \\
\text { WJF/PLLA }\end{array}\end{array}$ & $81 \pm 13.5$ & $1.12 \pm 0.034$ & 3.8 & $82 \pm 12.0$ & $4.3 \pm 0.10$ & $16.4 \pm 1.8$ \\
$\begin{array}{l}\text { composite } \\
\text { Treated }\end{array}$ & $87 \pm 8.5$ & $1.42 \pm 0.047$ & 5.1 & $121 \pm 13.4$ & $5.3 \pm 0.10$ & $18.1 \pm 2.3$ \\
$\quad$ WJF/PLLA & & & & & & \\
\hline
\end{tabular}

At weft direction:

1. Untreated WJF/PLLA

$$
71 \pm 8.7 \quad 0.78 \pm 0.063
$$

$79.2 \pm 9$

$0.91 \pm 0.057$

4.1

$81 \pm 9.4$

$3.62 \pm 0.08$

$14.3 \pm 1.5$ composite

$4.2 \quad 111 \pm 8.1$

$4.72 \pm 0.05$

$16.6 \pm 1.8$

2. Treated WJF/PLLA

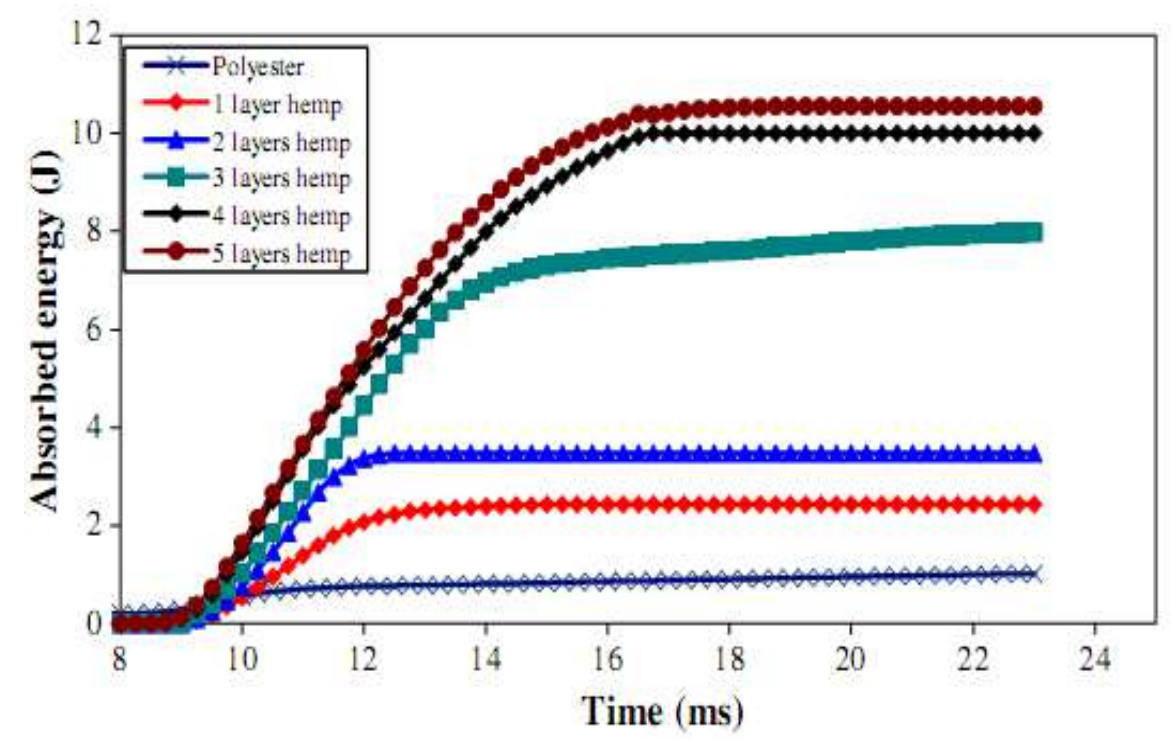

Figure 3: Absorb energy/time traces [9]

Influence of different orientation: According to result research by Sikarwar et al., [10], it can be seen that the energy absorbing capacity are increasing with increasing in thickness of the laminates. In their research, the laminates (0/90) lay-up laminates is much higher than other of lay-up laminates. The $(0 / 90 / 30 /-45)$ absorb more energy than the $(0 / 90 / 30 /-60)$ orientation. Thus, it is understood that energy absorption is dependent both on failure strain well as on Young's Modulus. 
Table 2: Experimental and theoretically predicted energy absorption capacity of the glass/ epoxy laminates [10]

\begin{tabular}{cccc}
\hline Lay-up sequence & $\begin{array}{c}\text { Thickness } \\
(\mathrm{mm})\end{array}$ & $\begin{array}{c}\text { Energy absorbed } \\
(\text { experimental })(\mathrm{J})\end{array}$ & $\begin{array}{c}\text { Energy absorbed } \\
\text { (predicted) }(\mathrm{J})\end{array}$ \\
\hline \multirow{3}{*}{$0 / 90$} & 1.5 & 27.09 & 27.73 \\
& 3 & 36.75 & 38.25 \\
& 4 & 66.63 & 65.34 \\
$0 / 90 / 30 /-60$ & 5 & 92.43 & 108.37 \\
& 1.5 & 22.23 & 22.81 \\
& 3 & 39.78 & 37.5 \\
$0 / 90 / 45 /-45$ & 4 & 57.19 & 49.59 \\
& 5 & 70.38 & 60.48 \\
\hline & 1.5 & 23.40 & 21.66 \\
$30 /-60 / 60 /-30$ & 4 & 33.84 & 37.50 \\
& 5 & 46.20 & 49.59 \\
& 1.5 & 67.33 & 58.59 \\
\hline & 3 & 18.90 & 19.44 \\
& 4 & 30.37 & 31.74 \\
& 5 & 42.93 & 39.78 \\
\hline
\end{tabular}

\section{Research Gap}

In the latest years, there have been many researchers involved in this field of natural fibre reinforced plastics [11]. Most of them are based study on the mechanical properties of composites reinforced with short and non-woven fibres [12, 13]. According to previous research [9], studied on low-velocity impact response of non-woven hemp fibre reinforced unsaturated polyester composites. In their research, focus on low velocity impact of non-woven natural fibre using varying layers.

Sikarwar et al., [10] studied influence of fibre orientation and thickness on the response of glass/epoxy composites subjected to impact loading. In experimental, glass/epoxy is laminated with orientation in order to determine the energy absorption capacity. Laminate with difference orientation [0/90], [0/90/30/-60], [0/90/45/-45], and [30/-60/60/-30] are used. Sas et al., [14] also studied on orientation permeability of unidirectional fabric. In their study, the characterization of orientation is performed by using numerical analysis ANSYS software. Although there has been research on orientation of material, but commonly uses a unidirectional.

\section{Conclusion}

Woven had not explored widely on kenaf natural fibre. Recently, most of the research focuses on tensile strength of natural fibre [15]. Energy absorption on woven natural fibre is better than nonwoven were proved by previous researches on woven flax fibre has greater embodied energy than a glass fibre [16]. From the result it can be summarized that woven on natural fiber are produced higher energy compared with non-woven. It is suggested to use four layers are necessary and comparable to the energy absorbed [8]. The effects of woven orientations are stronger than nonwoven fibre. According to the author knowledge, lack of information on affect orientation of impact loading by natural fibre, [9] in their research, studied on impact loading on fibre glass.

\section{Acknowledgment}

Authors acknowledged Universiti Tun Hussein Onn Malaysia (UTHM), Office for Research, Innovation, Commercialization and Consultancy Management (ORICC), Kementerian Pendidikan Malaysia (KPM) for funding this project through Research Acculturation Grant Scheme (RAGS Vot R019) 


\section{References}

[1] John Summerscales, Nilmini Dissanayake, Amandeep Virk, Wayne Hall. A review of bast fibres and their composites. Part 2 - Composites. Composites: Part A 41 (2010) 1336-1344.

[2] Igor M. De Rosa, Carlo Santulli, Fabrizio Sarasini. Acoustic emission for monitoring the mechanical behavior of natural fibre composites: A literature review. Composites: Part A 40 (2009) 1456-1469.

[3] S.H Masran, A.E Ismail, M.F Marian, A study of energy absorption performances of pultruded composites under quasi-static compressive loadings. Applied Mechanics and Materials (2014) 465:662-666.

[4] A.E Ismail, Effect of foam density and wall thickness interactions on the energy absorption performances. Applied Mechanics and Materials (2013) 315:665-669.

[5] H.M. Akil, M.F. Omar, A.A.M. Mazuki, S. Safiee, Z.A.M. Ishak, A. Abu Bakar. Kenaf fiber Reinforced Composites: A Review. Material and Design 32 (2011) 4107-4121.

[6] M.N Roslan, A.E Ismail, M.Y Hashim, M.H Zainulabidin, S.N.A Khalid, Modelling analysis on mechanical damage of kenaf reinforced composite plates under oblique impact loadings, Applied Mechanics and Materials 465 (2014) 1324-1328

[7] A.E Ismail, M.H Zainulabidin, M.N Roslan, A.L.M Tobi, N.H.M Nor. Effect of velocity on the impact resistance of woven jute fiber reinforced composites. Applied Mechanics and Materials (2014) 465:1277-1281.

[8] G.M. Arifuzzaman Khan, M. Terano, M.A. Gafur, M. Shamsul Alam. Studies On The Mechanical Properties Of Woven Jute Fabric Reinforced Poly( L -Lactic Acid) Composites. Engineering Science (2013).

[9] H.N. Dhakal, Z.Y. Zhang, M.O.W. Richardson, O.A.Z. Errajhi. The Low Velocity Impact Response Of Non-Woven Hemp fibre Reinforced Unsaturated Polyester Composites, Composite Structures 81 (2007) 559-56.

[10] Rahul S. Sikarwar, R. Velmurugan, N.K Gupta. Influence of Fiber Orientation and Thickness on the Response. Composite: part B 60 (2014) 627-636.

[11] Q.N. Tran, C.A. Fuentes, C. Dupont-Gillain, A.W.Van Vuure, I. Verpoest. Understanding the Interfacial Compatibility and Adhesion of Natural Coir Fibre Thermoplastic Composites. Composite Science and technology 63 (2013) 23-30.

[12] A.K. Rana, A. Mandala, S. Bandyopadhyay, Short jute fiber reinforced polypropylene composites: effect of compatibiliser, impact modifier and fiber loading. Composite Science and technology 63 (2003)801-806.

[13] Mohd Suhairil Meona, Muhamad Fauzi Othmana, Hazran Husaina, Muhammad Fairuz Remelia, Mohd Syahar Mohd Syawala, Improving tensile properties of kenaf fibers treated with sodium hydroxide. Proceeding engineering 41 (2012) 1587-1592.

[14] Hatice S. Sas, Eric B. Wurtzel, Pavel Simacek, Suresh G. Advani. Effect of Relative Ply Orientation on the through-thickness Permeability of Unidirectional Fabric. Composite Science and technology 96 (2014) 116-121.

[15] A.E Ismail, M.K Awang, M.H Sa'at, Tensile strength of natural fiber reinforced polyester composite, AIP Conf. Proc. 909 (2007) 174-179.

[16] Nilmini P. J., Dissanayake, J., Summerscales, S. M. Grove \& M. M. Singh, Energy use in the production of flax fiber for the reinforcement of composites. J Nat Fiber 2009;6(4):331-46. 